\title{
Consumer price sensitivity in Dutch health insurance
}

\author{
Machiel van Dijk - Marc Pomp • Rudy Douven • \\ Trea Laske-Aldershof • Erik Schut • Willem de Boer • \\ Anne de Boo
}

Received: 16 March 2007 / Accepted: 2 June 2008 / Published online: 17 August 2008

(C) The Author(s) 2008. This article is published with open access at Springerlink.com

\begin{abstract}
Aim To estimate the price sensitivity of consumer choice of health insurance firm. Method Using paneldata of the flows of insured between pairs of Dutch sickness funds during the period 1993-2002, we estimate the sensitivity of these flows to differences in insurance premium. Results The price elasticity of residual demand for health insurance was low during the period 1993-2002, confirming earlier findings based on annual changes in market share. We find small but significant elasticities for basic insurance but insignificant elasticities for supplementary insurance. Young enrollees are more price sensitive than older enrollees. Conclusion Competition was weak in the market for health insurance during the period under study. For the market-based reforms that are currently under way, this implies that measures to promote competition in the health insurance industry may be needed.
\end{abstract}

Keywords Health insurance $\cdot$ Consumer choice $\cdot$ Price elasticity

\section{JEL Classifications $\quad \mathrm{D} 12 \cdot \mathrm{I} 11 \cdot \mathrm{I} 18 \cdot \mathrm{L} 11$}

\section{Introduction}

Competition between health insurance firms is a central pillar of the market-based reforms which are currently being introduced in the Dutch health care sector. Hence it is important to have a good idea of the extent of competition in the market for health insurance. Earlier

\footnotetext{
M. van Dijk · R. Douven

Central Planning Bureau, P.O. Box 80510, 2508 GM The Hague, The Netherlands

M. Pomp (凶)

Economic Policy Analysis, Zandberglaan 10, 4818 GK Breda, The Netherlands

e-mail: info@marcpomp.nl

T. Laske-Aldershof $\cdot$ E. Schut

Erasmus University, Rotterdam, The Netherlands

W. de Boer · A. de Boo

Vektis, Zeist, The Netherlands
} 
research (summarised below) has indicated that competition among health insurance firms is rather weak. If this continues to be the case in more recent years, then additional measures to stimulate competition in this market may be called for.

In this paper we present new empirical estimates of an indicator of competition, the elasticity of residual demand for health insurance. This elasticity measures the loss in market share of a health insurer as a consequence of a unilateral increase in price, assuming other firms keep their prices constant. The elasticity of residual demand is an important determinant of the level of competition. If this elasticity is small, then insurers will be able to set prices substantially higher than marginal costs.

Our estimates are based on a dataset covering all Dutch citizens who obtained health insurance through one of the 20 sickness funds in 2002 (about $60 \%$ of total population). We constructed a set of panel data by exploiting the fact that health insurers had a regional monopoly prior to the introduction of competition in 1993. We use this initial setting to construct bilateral flows of insured during 1993-2002 between each pair of health insurance firms in our dataset. Regressing these bilateral flows on price differences between each pair of health insurance firms allows us to estimate price elasticities of residual demand. The advantage of using this dataset over previous work that relied on time series of market shares per firm, is that we are able to estimate differences in price elasticity for many different subgroups of the population. Another advantage is that looking at bilateral flows (rather than aggregate market shares) gives us sufficient degrees of freedom to correct (at least to some extent) for unobserved firm-specific effects.

The paper is structured as follows. The next section provides some background on the Dutch system of health insurance. Section "Health insurance in the Netherlands" summarises existing estimates of the price elasticity of health insurance in the Netherlands and some other countries. Section "Literature review" describes the data and the estimation method. Section "Data and method" presents estimation results. Section "Results" uses these results to calculate elasticities of residual demand. Section "Conclusions" concludes.

\section{Health insurance in the Netherlands}

The institutional setting before the reforms

Until 2006, the Dutch market for health insurance was split into two segments, distinguished mainly by income of the insured. The first segment, covering about $60 \%$ of the population, consisted of compulsory insurance for workers and their dependents with incomes below a certain threshold (2005: euro 32,600). This segment was served exclusively by so-called sickness funds: not-for-profit health insurers. Private insurers were not allowed to operate in this part of the market; these firms had to focus their activities exclusively on the part of the population with incomes above the income threshold of euro 32,600. Health care providers were heavily regulated, with respect to prices as well as entry. The regulatory regime differs in important respects between the two segments of the health insurance market. Sickness funds face a number of restrictions that mostly do not apply to private for-profit insurers. In particular, sickness funds must:

- Offer a basic insurance policy, the coverage of which is determined by the government;

- contract with every hospital;

- take part in the risk-equalisation scheme run by the government; 
- accept every citizen at the same nominal premium (community rating) for basic insurance, irrespective of expected health costs, during annual open enrolment periods.

It is important to stress that the insurance mandate, the legally standardized benefits, the open enrollment requirement and the system of risk equalization largely eliminate adverse selection. In the presence of adverse selection, premium differences would not only be a cause but also a consequence of switching by the insured. For example, those at risk for high health care costs might choose an insurer with more generous coverage. This type of selection would have seriously complicated the estimation of price elasticities.

Another implication of the features of the Dutch health insurance setting is that the classic supply/demand identification problem does not arise. Market supply is determined by the size of the population given the fact that insurance is mandatory, while individual insurers have to accept any paying customer and to offer him/her the same coverage. In effect, quantity is not a choice variable for an individual insurer.

As far as basic insurance is concerned, sickness funds were financed partly through income-related premiums set by the government, and partly by so-called nominal premiums set by the sickness funds themselves and paid out-of-pocket by the insured. In 2005 the nominal premium accounted for about $15-20 \%$ of the total premium. By varying the nominal premium, sickness funds were able to compete on price in the market for basic insurance. Sickness funds also sold supplementary insurance but via a separate legal entity, covering inter alia dental care, physical therapy and alternative medicine. None of the above restrictions applied to supplementary insurance. Sickness funds had to cover the costs of supplementary insurance entirely out of their premium income.

Basic insurance and supplementary insurance: tied sales?

In the Netherlands, the overwhelming majority of sickness funds enrolees (over 90\%) also bought voluntary supplementary insurance for health costs not covered by basic insurance. As already pointed out, open enrolment did (nor does) not apply to supplementary insurance. Moreover, almost all firms restricted supplementary insurance to those insured who purchase their basic policy from the same firm (Schut et al. 2004). This suggests that most enrolees chose a health insurer on the basis of the price for the total package (basic plus supplementary insurance). However, because of the lack of transparency of the market for supplementary insurance due to the proliferation of different policies, enrolees may have attached a greater weight to the price of basic insurance in their choice of sickness fund. For this reason, we will not a priori assume that consumers based their choice of sickness fund on the price of the total package (basic plus supplementary insurance).

\section{The post-reform setting}

In 2006 a major reform of the Dutch health care system was initiated. A new national health insurance scheme was introduced in which the social and private segments of the health insurance market were unified. All citizens have to buy standardized basic health insurance coverage at a community rated premium from a private health insurance firm. Health insurers have to accept all applicants and are compensated for enrollees with predictably high costs by risk-adjusted premium subsidies. In addition, the government started with a creating more room for competition at the supply side of the health care market, by a gradual deregulation of prices of hospitals, introducing more freedom for selective contracting of 
health providers by health insurers, and by improving the transparency of the market with respect to price and quality (although with respect to the latter there is still a long way to go). Taken together, these reforms imply a much greater role for market forces. Effective competition among health insurers is an important element of the reform, since this has to provide insurers with appropriate incentives to act as a prudent purchaser of care on behalf of their enrollees.

\section{Literature review}

The price elasticity of residual demand is an important statistic for gauging the level of extent of competition in a given market (Yang 2002). This elasticity measures the percentage drop in market share in response to unilateral increase in price by one firm, keeping prices at all other firms constant. Thus, the larger this elasticity (in absolute terms), the more competitive the market.

In summarising the empirical literature on price elasticities of residual demand in health insurance markets, it is important to stress that most studies look at the price elasticity of demand with respect to the out-of-pocket premium (the part of the premium directly paid by the insured). The out-of-pocket premium covers only a part of the insurance bill: the government and/or employers usually pay a substantial part of the premium. In the US, the out-of-pocket premium usually covers only $10-20 \%$ of the total premium, in Germany the share is about $50 \%$ while in the Netherlands, on average out-of-pocket premiums amount to $10-15 \%$ of the total medical expenses (Schut and Hassink 2002). Because in the Netherlands, employers and employees both pay an income-related amount irrespective of the sickness fund chosen, consumers pay the full out-of-pocket price differential between health insurers. This is different from the situation in Germany where consumers pay only a percentage of the price differential (Schut et al. 2003). In the US, there is a shift among employers from a percentage contribution to a fixed subsidy based on the cheapest health plan on the menu. As a consequence, employees increasingly pay the full price differential among different plans.

Table 1 summarises recent estimates from the literature of the out-of-pocket elasticity of residual demand in health insurance markets. Clearly, estimates differ widely, not only between countries but also within countries. Elasticity estimates for the Netherlands are low compared to Germany and the US. Indeed, raising the premium for basic insurance may be a profitable strategy for an average sickness fund, at least in the short run (Schut and Hassink 2002).

We should stress that a comparison of estimated price elasticities of health plan choice in different countries is not straightforward, because of different base levels of out-of-pocket premiums and market shares. For instance, in Germany out-of-pocket premiums are at least twice as high as the out-of-pocket premiums that typically paid by US employees with employment-based group insurance. Due to the higher level of out-of-pocket premiums in Germany the estimated price elasticities of plan choice in Germany are likely to be two to five times as large as in the US. Also, the German estimates refer to the choice of type of sickness fund, not to the choice of any specific sickness fund. 
Table 1 Out-of-pocket elasticities of demand for health insurance: literature survey

\begin{tabular}{llr}
\hline Author & Period & Elasticity \\
\hline A. The Netherlands & & \\
$\quad$ Schut and Hassink (2002) basic Insurance & $1996-1998$ & -0.3 \\
$\quad$ Schut and Hassink (2002) supplementary insurance & $1996-1998$ & -0.8 \\
$\quad$ Schut and Hassink (2002) basic + supplementary insurance & $1996-1998$ & -0.4 \\
$\quad$ Schut et al. (2003) & $1996-2000$ & $0.0-0.4$ \\
B. Germany & & $0.4-5.3$ \\
$\quad$ Schut et al. (2003) & $1996-2000$ & $-0.2-1.7$ \\
C. US & & $-0.1-1.5$ \\
$\quad$ Strombom et al. $(2002)^{\mathrm{c}}$ & 1995 & $1994-1995$ \\
$\quad$ Royalty and Solomon (1999) & & \\
\hline
\end{tabular}

a Most estimates are insignificant, the only exception being pensioners where a significant coefficient is found for supplementary insurance (the elasticity is -0.36)

${ }^{\mathrm{b}}$ Posiitive elasticity applies to pensioners; not significant

c Strombom et al. (2002) estimate total premium elasticities from which we have calculated out-of-pocket premium elasticities; the highest elasticities apply to young and to newly hired workers

${ }^{d}$ Higher elasticities for younger, healthier workers; Royalty and Solomon (1999) also present much higher estimates based on a model including fixed effects. However, these are unrepresentative for the whole population since fixed effects logits can only be estimated on the part of the population that has actually switched

\section{Data and method}

The dependent variable

\section{Starting point: individual cross-section data}

For the purposes of this research we have obtained access to the complete records of all 10 million Dutch citizens who were covered by one of the 20 sickness funds in 2002. ${ }^{1}$ This dataset is maintained by Vektis, a private firm that is owned by the Dutch federation of health insurers $(\mathrm{ZN})$. For estimation purposes we have excluded children who do not choose their own sickness fund, but are enrolled via their parents. This reduces the dataset to roughly 8.0 million observations.

\section{Transforming cross-section data into paneldata}

Estimating a price elasticity from a single cross-section is problematic, since it will not be possible to correct for unobserved firm-specific effects which could be correlated with prices, leading to a bias in the estimated coefficient for price. However, we are able to transform

\footnotetext{
${ }^{1}$ A small sickness fund, OZB, which worked exclusively for a large Dutch multinational company, is not included in the analysis. Furthermore, some firms merged during the period 1993-2002. We assume that the insured of the merged firms pay the premium of the largest of the merged firms. Using a weighted premium of the merged firms would have been better, but for supplementary insurance this required identifying a comparable supplementary policy for the merged firms. We do not have sufficient data to do this. For the firms that we observe in 2002 we take heterogeneity of supplementary insurance into account by including firm specific coefficients. However, this solution cannot be used to correct for within-firm heterogeneity. For basic insurance we checked whether including weighted premiums would alter our outcomes, and this turned out not to be the case. Weighted premiums where almost identical to the premiums of the largest of the merged firms, possibly because firms already coordinated their pricing behaviour prior to the formal merger. We also did a sensitivity analysis by excluding the Amsterdam region where a merged firm is the dominant insurer. This did not alter the estimation results either.
} 
a large part of our cross-section data into paneldata by exploiting the fact that until 1993, each sickness fund had a designated geographical area in which it was the sole provider of social health insurance. We make the following three assumptions (below we will return to the realism of these assumptions):

- All individuals in our dataset have been insured by a sickness fund uninterruptedly during the whole period 1993-2002 (not necessarily the same sickness fund).

- No individual in our dataset has moved between regions during the period 1993-2002.

- Individuals have switched at most once during the period 1993-2002.

Given these assumptions, it follows that in 1993 all individuals who are in our dataset in 2002, were insured by the monopolist sickness fund in their region of residence. Therefore, individuals who were still insured by the former regional monopolist in 2002 can be classified as non-switchers. On the other hand, individuals who are not insured by the former regional monopolist must have switched from the former monopolist to their current insurer.

Dropping observations for which these assumptions are unlikely to hold: Unfortunately, we do not know whether someone who is insured by a sickness fund in 2002 had been insured by a sickness fund during the whole period. Indeed, for some groups in the population, it is likely that a substantial share switched from private insurance to social health insurance. For example, the self-employed were not covered by social health insurance until 2000. Starting in 2000, this group also became legally obliged to buy insurance from one of the sickness funds (Schut et al. 2003). Therefore, we omit the self-employed-about 300,000 observations - from our empirical analysis.

Something similar applies to the elderly (Schut and Hassink 2002). In 1997, about 90,000 privately insured elderly suddenly became entitled to social health insurance because of a substantial increase in the income threshold below which they were eligible for social health insurance. Therefore, we also omit the elderly (aged 65 and over in 2002) —about 1.5 million observations - from our empirical analysis. Other research indicates that price elasticities for the elderly are much lower than for workers (Buchmueller 2000). Note that since we will estimate age-specific elasticise, omitting one age group will not bias the results.

Among the non-working of working age, many individuals have been working during some years in the period 1993-2002, but lost their jobs, resulting in a fall in income. If this fall in income led to an income below the threshold for sickness funds, then these individuals became eligible for social health insurance. If these individuals chose another sickness fund than the former regional monopolist, then our procedure would erroneously classify this group as switchers. Thus, we leave out this groups as well.

Finally, most individuals below age 25 in 2002 were insured through their parents in 1993. If their parents were privately insured in 1993, and if these individuals chose another sickness funds than the former regional monopolist, then this group is erroneously classified as switchers. Therefore we also leave out this group. This leaves us with all observations on workers aged 25-64. Since it is unlikely that workers have experienced a fall in income, it is likely that these workers were insured by a sickness fund in $1993 .^{2}$

\footnotetext{
2 There is one other group where similar problems might occur, but which we nevertheless include in our empirical analysis since we believe that for this group the problem is fairly small. This group consists of (mostly) women who re-entered the labour force. Some of these women may have been insured via their husband's private insurance policy before re-entering the labour force. After re-entering they may have become eligible for social health insurance. Of all working women between $0.5 \%$ and $1 \%$ are women who re-entered the labour force during the previous year (calculated from data provided by Statistics Netherlands). Only a minority of these women had husbands who were privately insured. Assuming this share to be equal to the share in the population as a whole yields one-third. Thus, the annual number of women erroneously classified
} 
Table 2 Descriptive statistics: number of switchers 1993-2002, by age and gender (workers)

\begin{tabular}{llllll}
\hline & \multicolumn{2}{l}{ Age in 2002 } & & \\
\cline { 2 - 6 } & $25-34$ & $35-44$ & $45-54$ & $55-64$ & Row total \\
\hline Women & & & & & \\
$\quad$ Number of obs & 605863 & 458189 & 297572 & 169258 & 1530882 \\
$\quad \begin{array}{l}\text { Number of switchers } \\
\quad \text { Percentage of switchers }\end{array}$ & 140638 & 74711 & 40014 & 20400 & 275763 \\
$\quad$ Men & 23.2 & 16.3 & 13.4 & 12.1 & 16.3 \\
$\quad$ Number of obs & 585885 & 511814 & 367300 & 140393 & 1605392 \\
$\quad$ Number of switchers & 160247 & 114771 & 77702 & 24418 & 377138 \\
$\quad$ Percentage of switchers & 27.4 & 22.4 & 21.2 & 17.4 & 22.1 \\
$\quad \begin{array}{l}\text { Total } \\
\quad \text { Number of obs }\end{array}$ & 1191748 & 970003 & 664872 & 309651 & 3136274 \\
$\quad$ Number of switchers & 300885 & 189482 & 117716 & 44818 & 652901 \\
$\quad$ Percentage of switchers & 25.3 & 19.4 & 17.3 & 14.7 & 19.2 \\
\hline
\end{tabular}

Moving between regions: If an individual moves from one region to another but stays with the same sickness fund, then our procedure results in erroneously classifying this individual as a switcher. It has been reported that annual movements between regions amount to 0.2$0.3 \%$ of all households enrolled in a sickness fund (Kalshoven 1999). Cumulated over 10 years this amounts to $2-3 \%$ of all households. This classification error is fairly small given that the percentage of switchers in our dataset is equal to roughly $20 \%$ of all households (see below).

Identifying regions: In order to determine which firm was the regional monopolist for a given individual, we used municipality codes. There are 496 municipalities in our dataset. Within each municipality we identify the former monopolist on the basis of market share. The largest firm is defined as the former monopolist. This correctly identified which firm was the former regional monopolist in most of the municipalities. However, the designated regions did not always coincide exactly with municipality borders: in quite a few cases one geographical area within a municipality was served by one firm while some other geographical area within the same municipality was served by another firm. In these cases, we will incorrectly classify individuals who had been insured by the smaller of these sickness funds as switchers or as non-switchers. Therefore, we used a cut-off point of $60 \%$ : if in a given municipality the largest firm had a market share in 2002 of $60 \%$ or more, then we included the municipality in the analysis, otherwise we omitted this municipality. In this way we exclude most municipalities where in 1993 there was a second large sickness funds active. ${ }^{3}$ Applying this rule leads us to exclude 65 municipalities and a drop in the number of cases of about one million. In section "Results" we discuss sensitivity analysis using another cut-off point.

Footnote 2 continued

as switcher amounts to only $0.2-0.3 \%$ at maximum. On the other hand, re-entrants are primarily found among the 25-45 year old. Given that the percentage of female switchers in these age groups in our data is about $20 \%$ of all households (see below), this classification error is fairly small.

3 As of 1999 the former regional monopolist still had a market share of $80 \%$ or more (De Bekker and Van den Brink 2002). Extrapolating to 2002 would lead to a market share of 70-75\%. Using this ratio of 2002 market shares to 1993 markets shares (i.e. 3/4), a 2002 market share of $60 \%$ would correspond to a 1993 market share of $80 \%$. This would imply that, if in 1993 another firm was active in this municipality, its 1993 market cannot have exceeded $20 \%(100-80 \%)$. 
Table 3 Switching 1993-2002: bilateral flows by age and gender, $\%$ of total market

Source: see text

\begin{tabular}{lllll}
\hline & \multicolumn{1}{l}{ Age } & & & \\
\cline { 2 - 5 } & $25-34$ & $35-44$ & $45-54$ & $55-64$ \\
\hline Women & & & & \\
Mean & 1.3 & 0.9 & 0.8 & 0.7 \\
SD & 2.1 & 1.7 & 1.5 & 1.4 \\
Men & & & & 1.2 \\
Mean & 1.5 & 1.3 & 1.2 & 1.0 \\
SD & 2.4 & 2.1 & 2.1 & 1.8 \\
\hline
\end{tabular}

Resulting dataset: If we follow the procedure just described, we obtain the dataset presented in Table 2. The table shows the total number of individuals in our dataset along with the number of individuals who have 'switched' from one sickness fund to another in the period 1993-2002, broken down by age (in 2002) and gender. Clearly the propensity to switch depends on age (the young switch more) and gender (men are more likely to switch). It also emerges quite clearly that the former regional monopolist still has a very large share of this market: $81 \%(100-19.2 \%)$ on average.

\section{From individual data to bilateral flows}

The paneldataset just created allows us to construct bilateral flows (by age and gender) from former regional monopolists to the sickness funds that have entered the region since 1993. Of the 20 firms in our dataset in 2002, 15 had been a regional monopolist until 1993. Of the other five firms, four entered the market since 1993 while one firm was active in 1993 but not as a regional monopolist: it shared 'its' region with another firm, so in that region there was a duopoly. We omitted this region from our dataset since in case of a duopoly our procedure for constructing paneldata breaks down.

With these numbers of firms, we can construct $15 \times 19=285$ bilateral flows: from each of 15 former regional monopolist to each of 19 other firms. Since we will calculate separate flows for men and women and for each of four age groups, the total dataset contains 2,280 observations. We will use these flows from former regional monopolists to new entrants into the regional market as our dependent variable. Note that this procedure implies that new entrants can only gain customers. In order to adjust for differences in the size of the regional markets, we will divide each flow by the size of the total regional market in 2002.

Table 3 presents summary statistics for the bilateral flows that result from these calculations. Each entry in the table shows the average number of individuals who switched from a former regional monopolist to another firm, as a percentage of the total size of the regional market for the relevant age/gender group in $2002 .{ }^{4}$ To arrive at the average total outflow from a regional monopolist, each entry in the table must be multiplied by 19 (since each former monopolist faces potential competition in its former designated region from 19 other firms). ${ }^{5}$

\footnotetext{
4 Since we are restricting our dataset to insured who were (probably) continuously insured during 1993-2002, the total market in 2002 was the same size as the total market in 1993.

5 Multiplying the figures in table 4.2. by 19 does not exactly reproduce the corresponding figures in table 4.1, since outflow rates differ between regions and firms.
} 
Table 4 Construction of premium variables

\begin{tabular}{|c|c|c|c|c|}
\hline \multirow[t]{2}{*}{ To firm } & \multicolumn{4}{|c|}{ From firm } \\
\hline & 1 & 2 & $\ldots$ & 15 \\
\hline$\overline{1}$ & - & p1-p2 & $\mathrm{p} 1-\mathrm{p} \ldots$ & p1-p15 \\
\hline 2 & p2-p1 & - & p2-p... & p2-p15 \\
\hline$\ldots$ & $\mathrm{p} \ldots-\mathrm{p} 1$ & $\mathrm{p} \ldots-\mathrm{p} 2$ & - & p...-p15 \\
\hline 20 & p20-p1 & p20-p2 & $\mathrm{p} 20-\mathrm{p} \ldots$ & - \\
\hline
\end{tabular}

Explanatory variables

\section{Prices}

Our main interest is in the effect of differences in price between any two sickness funds on switching between these two firms. In order to estimate this effect, we calculate for each pair of firms the difference in premium between these firms. This is illustrated in Table 4. Thus, our hypothesis is that a larger positive price differential between the incumbent (the former monopolist) and a regional entrant (all other firms) will result in a larger flow from the incumbent to the entrant.

Until 1996 there was almost no premium variation among sickness funds. All sickness funds charged the same premium for basic insurance of 90 euro's. The reason for this was that sickness funds were hardly at risk for the medical expenses of their enrollees. In 1996 the financial risk for sickness funds was raised from $3 \%$ to $15 \%$ of the difference between the expected and realized medical expenses of their enrollees (sickness funds received riskadjusted capitation payments for compensating most of the expected medical expenses). Supplementary insurance played hardly a role until 1996. Starting in 1996 this changed when dental care and physiotherapy where transferred from basic insurance to supplementary insurance.

Since our dependent variable does not consist of annual flows but flows of insured over a 10 year period (1993-2002), we use the average price difference between each pair of firms during these years as an explanatory variable. We use average prices for the years 1996-2002 since (as argued above) prior to 1996 switching cannot have taken place in response to price. ${ }^{6}$

The results of the procedure outlined in Table 4 are shown in Tables 5 and 6.

Using average prices may lead to a bias in estimated coefficients, since differences between average prices will tend to be smaller than differences in annual prices. This suggests that the bias is in the direction of overestimating the effect of prices: we are attributing observed switching behavior to smaller price differences than the annual price differences confronting the insured. ${ }^{7}$

\footnotetext{
6 One referee pointed out that it would have been preferable to base our calculations of flows between sickness funds on the same period, i.e. 1996-2002. However, we are unable to do this since we have to base initial market shares on the 1993 institutional setting, as pointed out in the text. Nevertheless, our approach is unlikely to bias our results, since price-induced flows date from after 1996. Any flows that took place in the years 1993-1996 must be due to other factors than price. Using average price differences over 1996-2002 or 1993-2002 does not change our results since it only alters the scaling of the price differences shown in tables 4.4 and 4.5 .

7 One referee pointed out that price changes of time may cancel out, while switching still leaves traces in the data. This can only happen in case of non-linear response to price differences. If a price differential of $\mathrm{x}$ euros always leads to y persons switching then this will not arise. Non-linear effects cannot be ruled out, for example price differentials may have to be larger than some threshold in order to make switching worthwhile; below this threshold no switching takes place. However, in our data we hardly see the type of price movement that might lead to such non-linearity, namely large price differences between a pair of firm in one year followed by a smaller price differentials in later years. Rather what we see is increasing price differentials over time.
} 


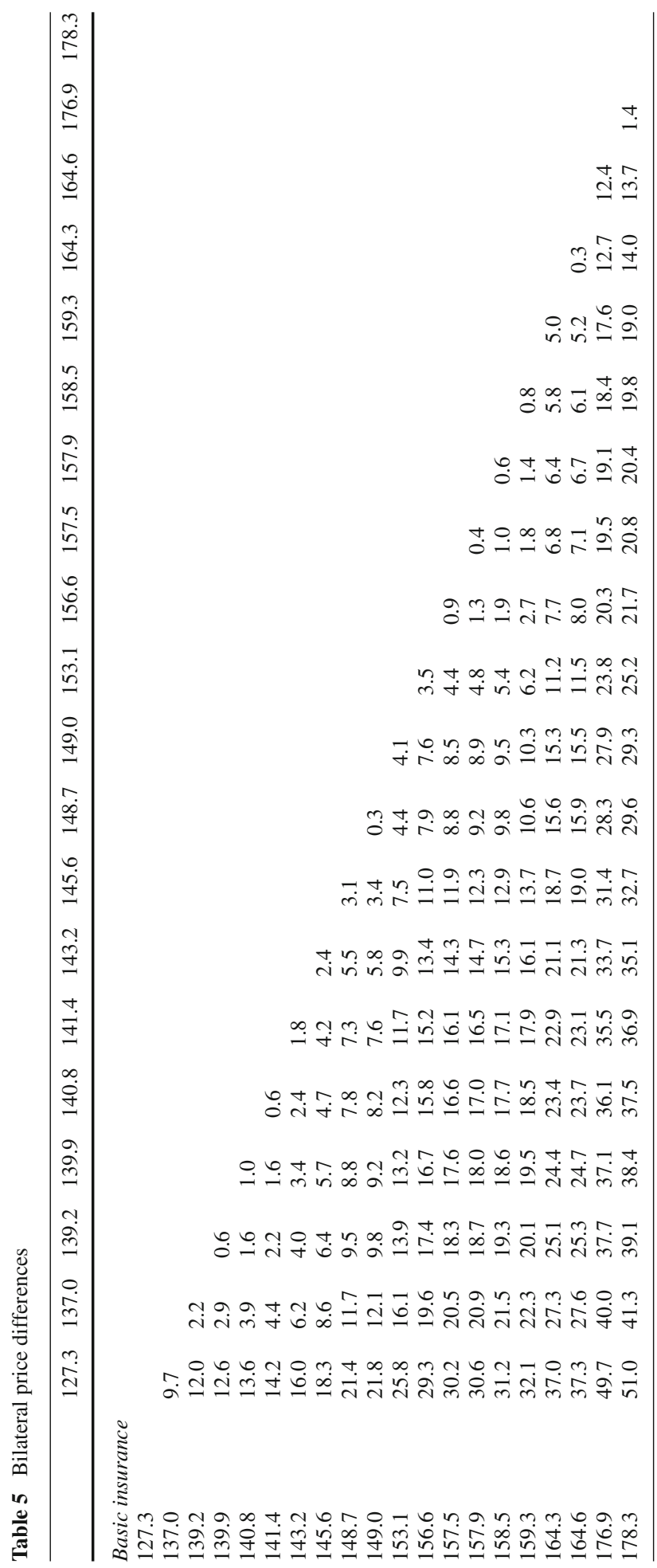




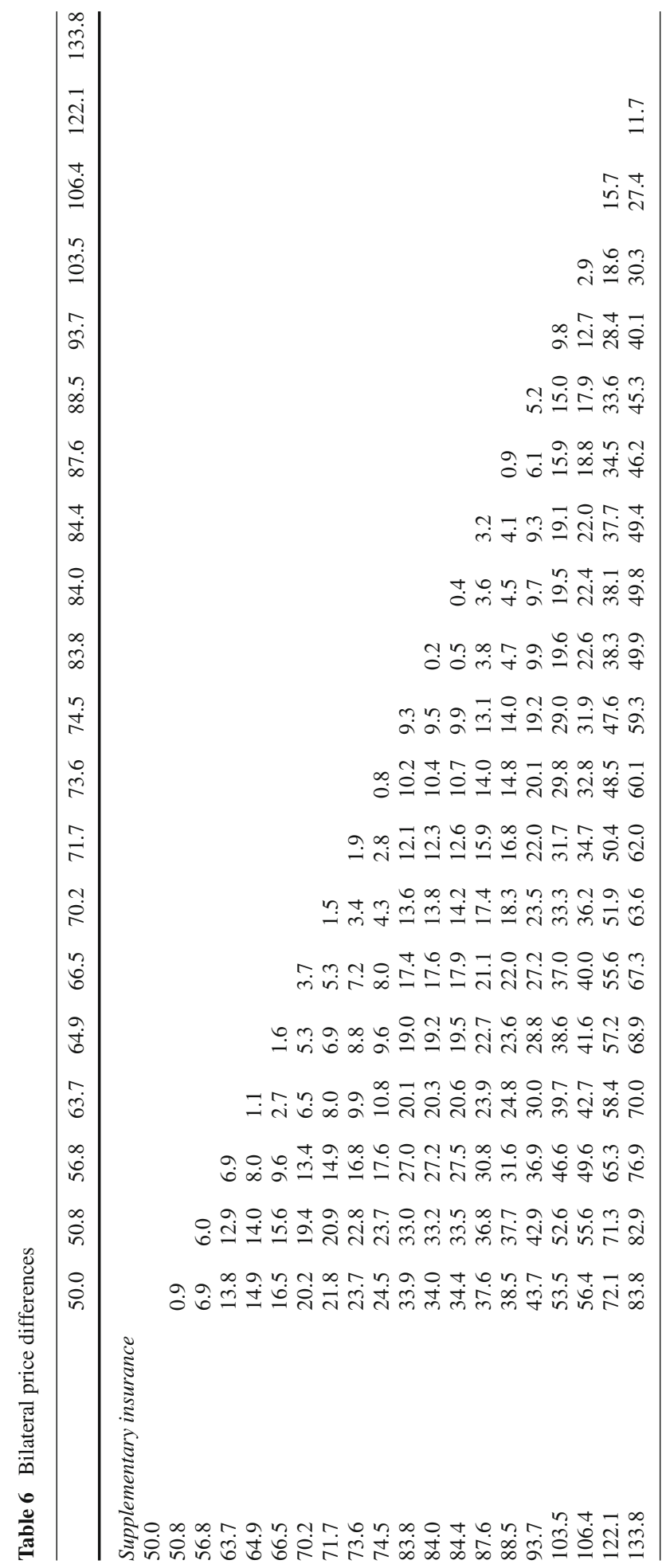


Table 7 Prices: average annual premium 1996-2002 (euro)
Source: iBMG database on health insurance premiums (unpublished)

\begin{tabular}{llll}
\hline Sickness fund & Basic insurance & $\begin{array}{l}\text { Supplementary } \\
\text { insurance }\end{array}$ & Total \\
\hline 1 & 148.7 & 50.8 & 199.5 \\
2 & 145.6 & 56.8 & 202.4 \\
3 & 158.5 & 50.0 & 208.5 \\
4 & 127.3 & 83.8 & 211.1 \\
5 & 139.9 & 74.5 & 214.4 \\
6 & 153.1 & 66.5 & 219.6 \\
7 & 149.0 & 71.7 & 220.8 \\
8 & 157.9 & 64.9 & 222.7 \\
9 & 139.2 & 84.4 & 223.6 \\
10 & 143.2 & 84.0 & 227.2 \\
11 & 164.3 & 63.7 & 228.0 \\
12 & 157.5 & 73.6 & 231.1 \\
13 & 164.6 & 70.2 & 234.8 \\
14 & 137.0 & 103.5 & 240.5 \\
15 & 159.3 & 88.5 & 247.8 \\
16 & 141.4 & 106.4 & 247.8 \\
17 & 140.8 & 122.1 & 262.9 \\
18 & 176.9 & 87.6 & 264.5 \\
19 & 178.3 & 93.7 & 272.0 \\
20 & 156.6 & 133.8 & 290.4 \\
\hline
\end{tabular}

For basic insurance, prices of different insurers refer to exactly the same product so we are dealing with a homogenous product. The coverage of the basic package is set by the government and service levels play at most a limited role, since health providers send their bills directly to sickness funds. Customers face no risk of slow reimbursement by sickness funds. Schut and Hassink (2002) also argue that sickness funds offer a standardised product: "Since sickness funds offer standardised benefits and are only starting to employ managed care activities, it is unlikely that price variation can be explained by differences in quality or efficiency in purchasing or organising medical care (Schut and Hassink 2002)." The same does not apply to supplementary insurance, where comparing policies is hampered by differences in coverage across policies and firms. We tried to solve this by selecting a supplementary package that is more or less identical across insurers. This package includes dental care for adults, physical therapy, and medical appliances such as spectacle-glasses and hearing aids. However, we cannot exclude the possibility that price differences reflect to some extent real differences in quality (i.e. coverage) across supplementary policies. It is also possible that consumers interpret differences in these prices as indicators of differences in quality, even if in reality this is not the case. In that case we could in theory find a positive elasticity of residual demand.

Table 7 shows average prices for basic insurance, supplementary insurance and the total package. Note that price differentials are fairly small but not negligible. The maximum savings for the total package amount to about 100 euro per year. Since premium differentials are fairly stable over time (see below), this implies that the present value of switching to a cheaper fund could be substantial for some consumers.

It is important to note that differences in prices between firms are fairly stable over time, in the following sense: a firm that is relatively expensive in year $t$ will also be relatively expensive in year $t+1$. This applies to both basic and supplementary insurance; especially in the 
Table 8 Prices: correlation over time and coefficient of variation

\begin{tabular}{lllll}
\hline Correlation $(\mathrm{t}, \mathrm{t}+1)$ & $\begin{array}{l}\text { Basic insurance } \\
\text { coefficient of } \\
\text { variation }\end{array}$ & Correlation $(\mathrm{t}, \mathrm{t}+1)$ & $\begin{array}{l}\text { Supplementary } \\
\text { insurance coefficient } \\
\text { of variation }\end{array}$ \\
\hline 1996 & 0.58 & 1.90 & $\mathrm{NA}$ & 47.93 \\
1997 & 0.98 & 9.54 & 0.96 & 43.20 \\
1998 & 0.79 & 10.36 & 0.95 & 58.11 \\
1999 & 0.91 & 7.45 & 0.98 & 55.90 \\
2000 & 0.86 & 9.72 & 0.97 & 45.25 \\
2001 & 0.82 & 15.69 & 0.95 & 50.17 \\
2002 & & 10.93 & & 26.20 \\
\hline
\end{tabular}

Source: Calculated from time series on prices

latter case correlations over time are very high. We also note that the spread in supplementary premiums is much larger than the spread in premiums for basic insurance as measured by the coefficient of variation $(100 \times$ standard deviation/mean $)$, possibly indicating heterogeneity in the coverage of supplementary insurance (see Table 8). This suggests that it is important to include firm specific coefficients in the model to be estimated.

\section{Age and gender}

We included age and gender as explanatory variables. In addition, these variables were interacted with the price variables in order to assess whether price elasticities depend on these characteristics.

\section{Firm specific constants}

Apart from price, we include three sets of firm specific constants that should pick up unmeasured firm-specific effects such as quality of service. These firm-specific effects are plausibly correlated with price, in which case our estimates would be biased. We address this potential problem as follows. First, we include a firm specific constant for each former monopolist $\left(\alpha_{i}\right)$. The constant for firm $i$ is included if firm $i$ is involved in a bilateral flow as a former monopolist. Second, we include a set of firm specific constants for firms that were not the former monopolist in a region $\left(\alpha_{j}\right)$. This firm specific constant is included if firm $j$ is involved in a bilateral flow. Third, we include a dummy variable for new sickness funds $(N E W)$.

The firm specific constants $\alpha_{i}$ and $\alpha_{j}$ cannot be included simultaneously. This is because including both $\alpha_{i}$ and $\alpha_{j}$ would result in perfect collinearity between the firm specific effects and price.

\section{Equations to be estimated}

We will estimate six different models: three models with total premium as the price variable and three models with separate variables for the price of basic and supplementary insurance. For each of these choices of price variables, we present results for a model without any of the firm specific coefficients defined in section "Data and method", with firm specific constants for the former regional monopolist $\left(\alpha_{i}\right)$ and with firm specific constants for entrants $\left(\alpha_{j}\right)$. In the first case, we also include a separate dummy $(N E W)$ for new firms (firms that were not 
active in any of the regional markets in 1993). In the second case, any effects of this dummy are picked up by the firm specific coefficients for entrants.

The firm specific constants in the latter two specifications are included in an attempt to correct for unobserved differences (e.g. coverage, quality, service level) across firms that might bias our results. To the extent that these differences are constant over time, including these dummies will avoid bias in the coefficients on price. However, we cannot exclude the possibility that differences in quality or service level changed over time, in which case a bias could still remain. This possibility arises mainly in the case of supplementary insurance, since the basic insurance package is completely standardized across firms.

Recall that the classic identification problem does not arise in this case: supply does not depend on price, since firms have to accept every insured wiling to pay the insurance premium.

The estimated equations with total premium as the price variable read as follows:

$$
\begin{aligned}
F_{i \rightarrow j, j \neq i}= & C+\beta_{1} \cdot A G E \cdot\left(\overline{P_{j}}-\overline{P_{i}}\right)+\beta_{2} \cdot \operatorname{MALE} \cdot\left(\overline{P_{j}}-\overline{P_{i}}\right)+\beta_{3} \cdot A G E \\
& +\beta_{4} \cdot M A L E+\varepsilon \\
F_{i \rightarrow j, j \neq i}= & \alpha_{i}+\gamma_{1} \cdot A G E \cdot\left(\overline{P_{j}}-\overline{P_{i}}\right)+\gamma_{2} \cdot \operatorname{MALE} \cdot\left(\overline{P_{j}}-\overline{P_{i}}\right)+\gamma_{3} \cdot A G E \\
& +\gamma_{4} \cdot M A L E+\gamma_{5} \cdot N E W+\varepsilon \\
F_{i \rightarrow j, j \neq i}= & \alpha_{j}+\tau_{1} \cdot A G E \cdot\left(\overline{P_{j}}-\overline{P_{i}}\right)+\tau_{2} \cdot \operatorname{MALE} \cdot\left(\overline{P_{j}}-\overline{P_{i}}\right)+\tau_{3} \cdot A G E \\
& +\tau_{4} \cdot M A L E+\varepsilon
\end{aligned}
$$

where

$$
\begin{aligned}
& F_{i \rightarrow j, j \neq i}=\text { The number of switchers from firm } i \text { to firm } j \text { during 1993-2002, as } \\
& \text { C }=\text { Constant } \\
& \alpha_{i} \quad=\quad \text { Firm specific constant for former regional monopolist } i \\
& \alpha_{j} \quad=\text { Firm specific constant for entrant } j \\
& \text { NEW } \quad=\text { Dummy variable taking on a value of } 1 \text { if } F_{i \rightarrow j, i \neq j} \text { concerns a flow to } \\
& \text { a new firm, } 0 \text { otherwise. } \\
& \left(\overline{P_{j}}-\overline{P_{i}}\right)=\text { Total average premium entrant minus total average premium former } \\
& =\text { An i.i.d. error term. }
\end{aligned}
$$
$M A L E=$ A dummy variable that takes on the value 1 if $F_{i \rightarrow j, i \neq j}$ concerns a flow of male switchers, 0 otherwise.

The estimated equations with separate variables for the price of basic and supplementary insurance are similar, except that we replace $\left(\overline{P_{j}}-\overline{P_{i}}\right)$, by two other variables, $\left(\overline{P_{j}^{B}}-\overline{P_{i}^{B}}\right)$ and $\left(\overline{P_{j}^{S}}-\overline{P_{i}^{S}}\right)$ where $B$ stands for basic insurance and $S$ for supplementary insurance. Note that we are including interaction terms with price for each age group. As a consequence, we do not (indeed, we cannot) include price separately (i.e., not interacted). In effect, we allow the coefficient(s) on price to vary freely across age groups. Note also that we also impose the effect of gender to raise or lower the whole age profile of the price-coefficient by the same absolute amount, irrespective of age. Allowing the age profile of the price coefficient to differ 
between men and women in an unconstrained way leads to very similar results. Ideally, we would also estimate the effect of other factors such as income and education. However this is precluded due to a lack of data.

\section{Calculating elasticities}

Because of the way we constructed our dataset, calculating elasticities on the basis of the estimated coefficient is rather complicated. The elasticity we are looking for is defined as follows:

$$
\varepsilon_{i}=\frac{\Delta Q_{i}}{\Delta \bar{P}_{i}} \frac{\overline{P_{i}}}{Q_{i, 1993}}
$$

where

$\Delta Q_{i}=$ net change in the number of insured at firm $i$ during the period 1993-2002.

$Q_{i, 1993}=$ the number of insured at firm $i$ at the beginning of the period 1993-2002.

$\Delta \bar{P}_{i} \quad=$ change in the average price over the period 1996-2002 of firm $i$.

$\bar{P}_{i} \quad=$ the average price over the period 1993-2002 of firm $i$.

If we define $S_{i j}$ as the number of switchers from firm $i$ to firm $j$, we can replace $\Delta Q_{i} / \Delta \overline{P_{i}}$ in Eq. 4 by:

$$
\Delta Q_{i} / \Delta \overline{P_{i}}=\left[\sum_{j=1, j \neq i}^{j=20} S_{i j}-\sum_{k=1, k \neq i}^{k=15} S_{k i}\right] / \Delta \overline{P_{i}}
$$

Equation 5 indicates that the change in the number of insured of firm $i$ as a consequence of raising its price, equals the change in each of the bilateral flows in which firm $i$ is involved. The first term between brackets represents the change in the flows from firm $i$ to other firms as a consequence of firm $i$ raising its price. The second term between brackets indicates the flows to firm $i$ from other firms as a consequence of firm $i$ raising its price. These flows can occur only from one of the 14 other firms which held a regional monopoly in 1993.

Next we substitute $F_{i j}$ for $S_{i j}$ using the following equation (this follows directly from the definition of $F_{i j}$ in Eqs. 1-3):

$$
F_{i j}=100 \cdot S_{i j} / Q_{i, 1993}
$$

where $F_{i j}=F_{i \rightarrow j, j \neq i}$, see Eq. 1

$$
\Delta Q_{i} / \Delta \overline{P_{i}}=\frac{Q_{i, 1993}}{100}\left[\sum_{j=1, j \neq i}^{j=20} F_{i j} / \Delta \overline{P_{i}}-\sum_{k=1, k \neq i}^{k=15} F_{k i} / \Delta \overline{P_{i}}\right]
$$

Since we are interested in the elasticity for an average firm, we replace $Q_{i, 1993}$ by $Q^{*}$, defined as the number of insured of the average incumbent firm. Furthermore we can calculate $\mathrm{dF}_{i j} / \mathrm{dP}_{i}$ and $\mathrm{dF}_{k i} / \mathrm{dP}_{i}$ in Eq. 7 by differentiating Eqs. 1-3 with respect to price. Using the fact that the first term in Eq. 7 is a summation over 19 identical terms while the second term is a summation over 14 identical terms we arrive at the following equation:

$$
\Delta Q_{i} / \Delta \overline{P_{i}}=\frac{Q^{*}}{100}\left[\sum_{j=1, j \neq i}^{j=20} \phi_{j, \text { price }}-\sum_{k=1, j \neq i}^{k=15}-\phi_{j, \text { price }}\right]=\frac{33 \phi_{\text {price }} Q^{*}}{100}
$$


where $\phi_{\text {price }}=$ the (sum of the) estimated coefficient(s) on price in Eqs. 1-3 for the relevant group; for example, for 25-34 year old working males, we would add up the coefficients on the price for this age group and the coefficient on gender.

Substituting (8) in (4) and dropping the subscript $i$ (since we are interested in the elasticity for the average firm) yields:

$$
\varepsilon=33 \cdot \bar{P} \cdot \phi_{\text {price }} / 100
$$

This elasticity can be used to answer the following question: how much smaller (in \%) would the number of insured of an average firm have been in 2002, if its average price during the period 1996-2002 had been 1\% higher, assuming all other firms had kept their prices at the observed level?

\section{Results}

\section{Estimated coefficients}

We report results based on WLS (weighted least squares) since diagnostic tests indicate heteroskedasticity in most cases. The main effect of using WLS instead of OLS is a substantial increase in $t$-values. ${ }^{8}$

Table 9 shows the estimation results for equations with total premium as the price variable, while Table 10 shows the estimation results for equations with the basic and supplementary insurance as separate explanatory variables. In order to avoid cluttering of tables we do not report estimated coefficients on firm specific coefficients or intercepts. We also omit the coefficient for new entrants (NEW), which was always significantly negative.

In all equations we find that the probability of switching falls with age and is larger for men than for women: this is in line with the descriptive statistics reported above.

Turning to the estimated coefficients for price, we find that including firm specific coefficients matters a great deal, in particular for supplementary insurance. Quite strikingly, including coefficients for regional entrants leads to insignificant results for total and supplementary insurance but not for basic insurance. This points to omitted firm characteristics and/or heterogeneity in the quality (probably coverage) of supplementary insurance. On the other hand, one fairly robust finding is the significantly negative coefficient on the price of basic insurance. In general, we find plausible age patterns: the estimated coefficient is larger in absolute term for younger enrollees. In equations where we distinguish between basic and supplementary insurance, we find that men are more sensitive to price than women.

\section{Choosing between models}

In order to choose between the six estimated models, we performed two sets of $F$-tests:

- First, we determined whether the model without firm specific constants is rejected in favour of models with firm specific constants; this was always the case.

\footnotetext{
8 By construction, the dependent variable lies between 0 and 100. In our data, all bilateral flows are a small percentage of the customer base of each insurer. However, there are quite a few zero's in our bilateral flow data. Hence a Tobit specification allowing for zero-censoring might seem more appropriate than WLS. However, Tobit estimates turn out to be close to the WLS estimates reported here. Moreover, although predictions of negative flows are in principle possible, in this case that does not pose a problem since a negative predicted flow simply means a predicted flow in the opposite direction of the actual flow.
} 
Table 9 Estimation results, total premium, WLS

\begin{tabular}{|c|c|c|c|c|c|c|}
\hline \multirow[t]{2}{*}{ Variable } & \multicolumn{2}{|c|}{$\begin{array}{l}\text { No firm specific } \\
\text { constants }\end{array}$} & \multicolumn{2}{|c|}{$\begin{array}{l}\text { With firm specific } \\
\text { constants } \alpha_{i}\end{array}$} & \multicolumn{2}{|c|}{$\begin{array}{l}\text { With firm specific } \\
\text { constants } \alpha_{j}\end{array}$} \\
\hline & Estimate & $t$-value & Estimate & $t$-value & Estimate & $t$-value \\
\hline$A G E$ 35-44 & -0.338 & -2.466 & -0.115 & -1.953 & -0.116 & -3.222 \\
\hline$A G E$ 45-55 & -0.493 & -3.703 & -0.170 & -2.885 & -0.181 & -5.195 \\
\hline$A G E$ 55-64 & -0.625 & -4.906 & -0.233 & -4.052 & -0.230 & -6.845 \\
\hline$M A L E$ & 0.341 & 4.186 & 0.125 & 3.319 & 0.061 & 3.103 \\
\hline$A G E 25-34\left(\overline{P_{j}}-\overline{P_{i}}\right)$ & -0.009 & -2.718 & -0.006 & -3.367 & 0.000 & 0.194 \\
\hline$A G E 35-44\left(\overline{P_{j}}-\overline{P_{i}}\right)$ & -0.006 & -2.329 & -0.004 & -2.464 & 0.001 & 0.950 \\
\hline$A G E 45-54\left(\overline{P_{j}}-\overline{P_{i}}\right)$ & -0.006 & -2.439 & -0.003 & -2.125 & 0.001 & 1.292 \\
\hline$A G E 55-64\left(\overline{P_{j}}-\overline{P_{i}}\right)$ & -0.006 & -2.852 & -0.002 & -1.580 & 0.001 & 2.294 \\
\hline $\operatorname{MALE}\left(\overline{P_{j}}-\overline{P_{i}}\right)$ & -0.003 & -1.463 & -0.002 & -1.487 & -0.001 & -1.075 \\
\hline $\operatorname{Adj} R^{2}$ & 0.034 & & 0.211 & & 0.305 & \\
\hline $\mathrm{N}$ & 2128 & & 2128 & & 2128 & \\
\hline
\end{tabular}

Table 10 Estimation results, basic and supplementary premium, WLS

\begin{tabular}{|c|c|c|c|c|c|c|}
\hline \multirow[t]{2}{*}{ Variable } & \multicolumn{2}{|c|}{$\begin{array}{l}\text { No firm specific } \\
\text { constants }\end{array}$} & \multicolumn{2}{|c|}{$\begin{array}{l}\text { With firm specific } \\
\text { constants } \alpha_{i}\end{array}$} & \multicolumn{2}{|c|}{$\begin{array}{l}\text { With firm specific } \\
\text { constants } \alpha_{j}\end{array}$} \\
\hline & Estimate & $t$-value & Estimate & $t$-value & Estimate & $t$-value \\
\hline$A G E$ 35-44 & -0.340 & -2.559 & -0.114 & -1.901 & -0.140 & -3.711 \\
\hline$A G E$ 45-55 & -0.499 & -3.865 & -0.172 & -2.875 & -0.213 & -5.838 \\
\hline$A G E$ 55-64 & -0.630 & -5.100 & -0.233 & -4.005 & -0.266 & -7.377 \\
\hline$M A L E$ & 0.345 & 4.259 & 0.125 & 3.298 & 0.060 & 2.827 \\
\hline$A G E 25-34\left(\overline{P_{j}^{B}}-\overline{P_{i}^{B}}\right)$ & -0.008 & -1.415 & -0.006 & -2.514 & -0.008 & -4.479 \\
\hline$A G E 35-44\left(\overline{P_{j}^{B}}-\overline{P_{i}^{B}}\right)$ & -0.005 & -0.953 & -0.003 & -1.704 & -0.004 & -3.488 \\
\hline$A G E 45-54\left(\overline{P_{j}^{B}}-\overline{P_{i}^{B}}\right)$ & -0.005 & -1.160 & -0.003 & -1.470 & -0.003 & -2.336 \\
\hline$A G E 55-64\left(\overline{P_{j}^{B}}-\overline{P_{i}^{B}}\right)$ & -0.002 & -0.438 & -0.002 & -1.052 & -0.002 & -1.694 \\
\hline $\operatorname{MALE}\left(\overline{P_{j}^{B}}-\overline{P_{i}^{B}}\right)$ & -0.009 & -2.142 & -0.002 & -0.922 & 0.000 & 0.420 \\
\hline$A G E 25-34\left(\overline{P_{j}^{S}}-\overline{P_{i}^{S}}\right)$ & -0.009 & -2.791 & -0.007 & -3.727 & 0.001 & 1.107 \\
\hline$A G E 35-44\left(\overline{P_{j}^{S}}-\overline{P_{i}^{S}}\right)$ & -0.006 & -2.547 & -0.005 & -3.123 & 0.001 & 1.823 \\
\hline$A G E 45-54\left(\overline{P_{j}^{S}}-\overline{P_{i}^{S}}\right)$ & -0.006 & -2.575 & -0.004 & -2.834 & 0.001 & 1.812 \\
\hline$A G E 55-64\left(\overline{P_{j}^{S}}-\overline{P_{i}^{S}}\right)$ & -0.007 & -3.436 & -0.004 & -2.555 & 0.001 & 2.455 \\
\hline $\operatorname{MALE}\left(\overline{P_{j}^{S}}-\overline{P_{i}^{S}}\right)$ & -0.002 & -0.766 & -0.002 & -1.362 & -0.001 & -1.117 \\
\hline $\operatorname{Adj} R^{2}$ & 0.0385 & & 0.2074 & & 0.3126 & \\
\hline $\mathrm{N}$ & 2128 & & 2128 & & 2128 & \\
\hline
\end{tabular}

- Second, we assessed whether equality of coefficients on basic and supplementary premium is rejected in favour of including these as two separate explanatory variables; this was also the case.

Therefore, on statistical grounds we are able to narrow the number of models down to just two: with separate price variables basic and supplementary premium, either with firm specific 
Table 11 Elasticities

\begin{tabular}{|c|c|c|c|c|c|c|c|c|}
\hline & \multicolumn{4}{|c|}{ Based on equations including $\alpha_{i}$} & \multicolumn{4}{|c|}{ Based on equations including $\alpha_{j}$} \\
\hline & \multicolumn{2}{|l|}{ Women } & \multicolumn{2}{|l|}{ Men } & \multicolumn{2}{|l|}{ Women } & \multicolumn{2}{|l|}{ Men } \\
\hline & Elasticity & $t$-value & Elasticity & $t$-value & Elasticity & $t$-value & Elasticity & $t$-value \\
\hline \multicolumn{9}{|c|}{ Basic insurance } \\
\hline Age 25-34 & -0.30 & -2.51 & -0.38 & -1.84 & -0.41 & -4.48 & -0.39 & -2.68 \\
\hline Age 35-44 & -0.17 & -1.70 & -0.25 & -1.34 & -0.22 & -3.49 & -0.19 & -1.70 \\
\hline Age 45-55 & -0.14 & -1.47 & -0.22 & -1.21 & -0.15 & -2.34 & -0.12 & -1.08 \\
\hline Age 55-64 & -0.10 & -1.05 & -0.18 & -0.99 & -0.10 & -1.69 & -0.08 & -0.72 \\
\hline \multicolumn{9}{|c|}{ Supplementary insurance } \\
\hline Age 25-34 & -0.18 & -3.73 & -0.22 & -2.81 & 0.03 & 1.11 & 0.01 & 0.28 \\
\hline Age 35-44 & -0.13 & -3.12 & -0.17 & -2.37 & 0.03 & 1.82 & 0.01 & 0.43 \\
\hline Age 45-55 & -0.12 & -2.83 & -0.16 & -2.20 & 0.03 & 1.81 & 0.01 & 0.40 \\
\hline Age 55-64 & -0.10 & -2.55 & -0.14 & -2.03 & 0.04 & 2.46 & 0.02 & 0.72 \\
\hline
\end{tabular}

Note: $t$-values calculated using the delta method

constants for former regional monopolists $\left(\alpha_{i}\right)$ or with firm specific constants for firms that are new to the region $\left(\alpha_{j}\right){ }^{9}$

\section{Sensitivity checks}

In order to test the robustness of our findings to changes in the underlying assumptions, we did two sensitivity checks. First, in selecting the municipalities to be included in the analysis, we raised the cut-off point from $60 \%$ to $75 \%$ (see section "Data and method"). This lead to discarding 1,39 million observations and slightly higher (and statistically more significant) estimates. Second, rather than using average prices for the period 1993-2002 we included average prices for the period 2000-2002. Again this yielded essentially the same results, which is consistent with the fact reported in section "Data and method" that differences in premium tend to be stable over time.

\section{Elasticities}

Table 11 presents elasticity estimates for our preferred specifications. We find plausible age effects: estimated elasticities fall (in absolute value) with age. Also we find consistently that men are more responsive to price than are women. Perhaps the most striking result is that these elasticities are so small. Recall that these elasticities measure the cumulative effect after 7 years of keeping price $1 \%$ above the price of competitors. However, this does not means that we can derive annual elasticities simply by dividing the elasticities reported in Table 11 by 7 . Some insured may have switched to another firm early on (say in 1997), and stayed with that firm because this turned out to be the right choice in following years. Given the high correlation of prices over time noticed in section "Data and method", this is a plausible scenario. This reasoning suggests that the elasticities in Table 11 should be interpreted as an upper limit for the annual elasticity.

We should also point out that, since we are restricting our data to those who were insured continuously during the period 1993-2002, we are omitting new customers: new entrants to

9 Looking at the adjusted R-squared, the equations with $\alpha_{j}$ consistently have the highest explanatory power. 
the labour market and the self-employed. These groups are likely to be more price-sensitive (Schut et al. 2003).

\section{Conclusions}

The price elasticity of residual demand is an important empirical measure of the intensity of competition in a market. Obtaining reliable estimates for this elasticity requires paneldata that are often not available. By using changes in the regulatory setting of Dutch health insurance, we were able to construct a set of paneldata on the bilateral flows of insured between each pair of health insurance firms in the Netherlands. This results in a far richer dataset for estimating price elasticities then had been available thus far. Our results indicate that the price elasticity of residual demand for social health insurance was low during the period 19962002, confirming earlier findings based on annual changes in market share. We find small but significant elasticities for basic insurance but insignificant elasticities for supplementary insurance. Young enrollees are more price sensitive than older enrollees.

We had to make a number of assumptions in order to be able to estimate price elasticities from the data at hand. Although we believe that these assumptions are justifiable, they are not literally correct for all our observations. As a result, our estimates may be biased. Clearly, it would have been preferable to work with real paneldata, but these are not available for the bilateral flows we are interested in.

The main policy implication of our finding is that competition was weak in the market for health insurance during the study period. Recent experience seems to contradict this finding. In 2006, the year of the introduction of the new health insurance law, the number of insured switching health insurers increased to almost $20 \%$ of the Dutch population. However, this switching rate is likely to be an all-time high phenomenon, due to the fact that all citizens faced a drastically changed health insurance policy and many of them got the option to join a group contract. Indeed, in 2007 the number of switchers fell again to less than 5\%. Therefore, an active government policy to facilitate consumer choice by lowering search and switching costs (e.g. by providing consumer information and by standardizing switching rules and procedures) is likely to be needed to support competition in the health insurance market.

Open Access This article is distributed under the terms of the Creative Commons Attribution Noncommercial License which permits any noncommercial use, distribution, and reproduction in any medium, provided the original author(s) and source are credited.

\section{References}

Buchmueller, T. C. (2000). The health plan choices of retirees under managed competition. Health Services Research, 35(5), 949-976.

De Bekker, P., \& Van den Brink, R. (2002). Geconcentreerd Dereguleren. The Hague: Ministry of Health.

Kalshoven, C. (1999). Ziekenfondsverzekerden: zit er beweging in? Openbare Uitgaven, 40-47.

Royalty, A. B., \& Solomon, N. (1999). Health plan choice: Price elasticities in a managed competition setting. The Journal of Human Resources, 34(1), 1-41.

Schut, F. T., \& Hassink, W. H. J. (2002). Managed competition and consumer price sensitivity in social health insurance. Journal of Health Economics, 802, 1-21.

Schut, F. T., Greß, S., \& Wasem, J. (2003). Consumer price sensitivity and social health insurer choice in Germany and the Netherlands. International Journal of Health Care Finance and Economics, 3, 117-138.

Schut, F. T., Laske-Aldershof, T., \& De Bruijn, D. (2004). Effecten van de aanvullende ziekenfondsverzekering op de hoofdverzekering: Een theoretische en empirische analyse. Rotterdam: iBMG, Erasmus MC. 
Strombom, B. A., Buchmueller, T. C., \& Feldstein, P. J. (2002). Switching costs, price sensitivity and health plan choice. Journal of Health Economics, 21, 89-116.

Yang, S.-P. (2002). Identifying a dominant firm's market power among sellers of a homogeneous product: An application to Alcoa. Applied Economics, 34(11), 1411-1419 (Aluminum Company of America). 